\title{
The effects of vehicle restraint systems on road safety
}

\author{
Marcin Budzynski ${ }^{1}{ }^{*}$, Krzysztof Wilde ${ }^{1}$, Kazimierz Jamroz ${ }^{1}$, Jacek Chroscielewski ${ }^{1}$, Wojciech Witkowski $^{1}$, Stanislaw \\ Burzynski ${ }^{1}$, Dawid Bruski ${ }^{1}$, Lukasz Jelinski ${ }^{1}$ and Eukasz Pachocki ${ }^{1}$ \\ ${ }^{1}$ Gdańsk University of Technology, Faculty of Civil and Environmental Engineering, 11/12 Narutowicza st., 80-233 Gdańsk, Poland
}

\begin{abstract}
Key to understanding the needs and tools of road infrastructure management for preventing runoff-road crashes or minimising their consequences, is to identify the hazards and sources of hazards caused by wrong or improper use of road safety devices and identify errors in the design, structure, construction and operation of road safety devices. Studying such an extended scope of the problem required fieldwork and surveys with road authorities, designers, road safety auditors and road maintenance services. An outline of new guidelines could only be developed after understanding the effects of restraint systems, the design, additional elements, type of road and safety barrier location on a road or engineering structure and the road and traffic conditions on their functionality and safety. The paper will present the preliminary results of this research (research project - ROSE). One way to understand the functionality of road safety devices is to build numerical models and conduct simulation tests of virtual crash tests. The article presents the scope of work conducted as part of an effort to develop new vehicle restraint system guidelines.
\end{abstract}

\section{Introduction}

Road infrastructure and roadsides can be a factor causing road accidents when road user errors occur (e.g. elements that are not easily comprehended or clear, poorly organised traffic, curbed visibility, geometric parameters not adequate for the speeds) and have a strong influence on accident severity, especially where run-off-road accidents are concerned.

Run-off-road accidents and their consequences can be reduced by improving the road and street network, completing and reconstructing the existing network, developing and implementing "self-explanatory roads", developing and implementing "forgiving roads" and providing road signs and markings that are more understandable and road user friendly.

One of the devices supporting these actions is the use of road safety barriers. Before appropriate steps are taken, it is necessary to recognise the conditions in which hazards on the road occur and the effectiveness of the equipment used. Unfortunately, this kind of research is still lacking in Poland. To change that, a research project was launched focussing on road safety devices with particular emphasis on safety barriers. The results of the project can be useful for more than just Poland's road network, and can in fact help to improve roadside safety across Europe because of the scale of the research.

The main goal of the ROSE project (Road Safety Equipment) is to conduct comprehensive tests and analyses of various vehicle restraint systems including those defined under standard PN-EN 1317 and types of supporting structures defined under standard PN-EN 12767 deployed on roads and engineering structures. The work is to include preliminary tests of road safety equipment already in operation, additional site tests for selected crash tests, extended numerical tests and comprehensive analyses to help formulate road safety equipment suggestions and recommendations. The main project result is a method for selecting optimal systems to prevent errant vehicles in relation to: the type and severity of the hazard, road class, volume and structure of vehicle streams and traffic conditions (vehicle speeds) on the roads. The project aims to use and further develop the most modern numerical simulations of crash tests. Figure 1 shows the diagram of project delivery.

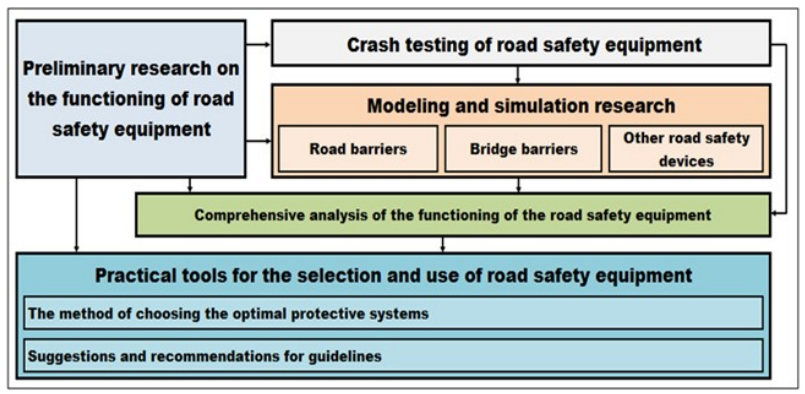

Fig. 1. The diagram of project delivery

So far, a significant number of studies have been conducted to determine the effect of traffic volume and road geometry on traffic accidents. These studies have shown that improving the geometry of the roadway can significantly reduce the number and consequences of accidents. A lot of the research looks at how the roadside changes safety. Traffic accident statistics in many countries show that about a quarter of all fatalities are caused by errant vehicles.

\footnotetext{
* Corresponding author: mbudz@.pg.edu.pl
} 
A run-off-road collision describes the primary road event in which a vehicle leaves the roadway as a result of loss of stability or sudden change of direction of travel (forced by speeding, loss of traction, etc.). Although occasionally after such collisions vehicles can return to the roadway, it very often leads to dangerous secondary events such as: roll-over, driving into a ditch, hitting an embankment or an object or roadside device e.g.: running into a road barrier, hitting a tree, a pole or a road sign [1]. The study of available literature shows that some researchers tried to establish the influence of selected road parameters (width of the roadway [2], type and width of the road shoulder [3]), road structures (bridges, culverts, road signs) [4, 5], obstacles along the road (trees, posts[6, 7]) and road equipment (road barriers and enclosures) $[8,9]$ on the risk of run-off-road collisions. The results of their research were used to model and simulate the effects of various combinations of geometric parameters and the road and traffic parameters on the frequency and effects of accidents. Based on the models, a set of preventive measures was developed and it was shown that the frequency of events can be significantly reduced by increasing lane and shoulder width, widening the central reservation, widening the roadway at bridge entrance, moving and removing dangerous road objects, decreasing the gradient of slopes and escarpments of ditches and introducing barriers and other safety systems [10]. More recent research focussed on roads that forgive driver error, for which the roadside obstacle-free zones turned out to be important $[11,12]$. Using the results of field research, mathematical modelling and computer simulation, the recommended widths of the obstacle-free area, the distance from the roadway and the height of the road barriers were determined [13]. A tree located too close to the roadway, a bad structure of a pole or road sign, a poorly designed or installed safety barrier system are the subjects of study, research and preparation of standards, guidelines, or examples of good practice [14]. The main consequence of hazards on the roadside is not the probability of an accident, but its severity [15]. The severity of road accidents in Poland results primarily from improperly designed or used road infrastructure. This is the consequence of the absence or poorly formulated regulations and failure to apply road safety standards [budzyński matec]. One of the most important projects implemented in Europe was RISER (Roadside Infrastructure for Safer European Roads) [16]. The project was designed to determine the behaviour of drivers (in adjusting speed) in relation to the conditions encountered. What was found was that the correlation between the occurrence of the central reservation and the type of barrier and also the dependence of the vehicle's road position on the obstacle type [17] indicates that the best current estimates of the effects of median barriers are a $30 \%$ increase in accident rate, a $20 \%$ reduction in the chance of sustaining a fatal injury given an accident, and a $10 \%$ reduction when sustaining a personal injury given an accident. Within the scope of research on the impact of road barriers and the roadside environment on road traffic safety other studies were conducted, including test results, which demonstrated that the development of a safe roadside and the correct use of vehicle restraint systems are key to improving the safety of road infrastructure users. It is also important for research to include actual speeds of vehicles [18] . It is speed that is the primary determinant of accident severity of roadside-related accidents.

Another major European project on the use of safety barriers and their effect on safety was the SAVeRS project [20] which helped to build tools for roadside safety management.

Experimental studies on road safety were first conducted in the US in the early 1950s. Today's experimental crash tests are prepared and conducted under strict procedures set out in the standards, EN 1317. With high costs of field tests, new research methods were investigated. The new era of research on developing and analysing road safety equipment goes back to the introduction of computer mechanics. First used in the 1960s for military purposes, numerical simulations were used as analytical tools. They were first used for civilian applications in the late 1980s with computer crash simulations. This was supported by the commercial version of the programme LS-DYNA, Hallquist (2007). Simulations of crash tests can also be done in the PAM-CRASH or ABAQUS EXPLICIT programmes. Experimental tests, modelling, simulation, validation and experimental verification of crash tests are all covered extensively in numerous research articles and development work reports [21,22]. The literature on numerical research on different types of crashes with road safety equipment is very extensive [23-26] have conducted detailed numerical modelling and simulations of crash tests that are required for containment level H1 under the standard EN 1317. The works [27, 28] present numerical modelling and simulation of non-modified (straight line barrier) and modified (curved barrier) crash tests, type TB11 and TB32. There was also an analysis of how the systems behave when crashed into by a bus [29].

\section{Crash tests}

A detailed review was conducted of previous safety barrier fieldwork to create a crash test database. An analysis of generally available reports and reports obtained by the authors helped to identify a set of problems which were investigated poorly or not at all. The following crash tests were performed (fig. 2.):

- TB32 crash test, conducted in accordance with standard PN EN-1317:2010 for a road wire rope barrier for a section of a barrier installed on a curve with a radius of 400 metres. (Deviation from the standard: the barrier on a horizontal curve, the rest follows the rules of the standard). In addition, a second crash was conducted in the same place. Justification: Little is known about barrier behaviour on horizontal curves, in 
particular when the barrier is hit on the inner (convex)edge of road on a horizontal curve. Of particular importance for identifying the potential width of the obstacle-free zone behind the barrier.

- TB32 crash test, conducted in accordance with standard PN EN-1317:2010 for a road steel barrier for a section of a barrier installed on a curve with a radius of 400 metres. (Deviation from the standard: the barrier on a horizontal curve, the rest follows the rules of the standard). Justification: Little is known about barrier behaviour on horizontal curves, in particular when the barrier is hit on the inner (convex) edge of road on a horizontal curve. Of particular importance for identifying the potential width of the obstacle-free zone behind the barrier.

- TB11 crash test, conducted in accordance with standard PN EN-1317:2010 for a road steel bridge parapet (low) mounted on a concrete plate with a 14 cm high kerb. Justification: Need to better understand vehicle behaviour upon hitting the kerb and parapet with special emphasis on the ASI parameter. Lack of sufficient baseline materials for numerical tests.

- TB51 crash test, conducted in accordance with standard PN EN-1317:2010 for a road steel bridge parapet (low) mounted on a concrete plate with a 14 cm high kerb. Justification: Need to better understand vehicle behaviour upon hitting the kerb and parapet with special emphasis on the ASI parameter. Lack of sufficient baseline materials for numerical tests.

- TB32 crash test conducted in accordance with standard PN EN-1317:2010 for the connection between a road wire rope barrier with a steel barrier. Justification: Need to better understand system behaviour and the effect on the vehicle for a frequently used connection in Poland. Lack of sufficient baseline materials for numerical tests.

- TB51 crash test, conducted in accordance with standard PN EN-1317:2010 for a steel barrier and lighting column placed within the barrier's working width. A steel barrier H2-W4-A, column class HE100. Justification: A frequent occurrence in Poland to have objects placed within the barrier's working width (lighting columns, gantries, etc.). Poor understanding of how the system works and the consequences of a crash, in particular involving an errant vehicle.

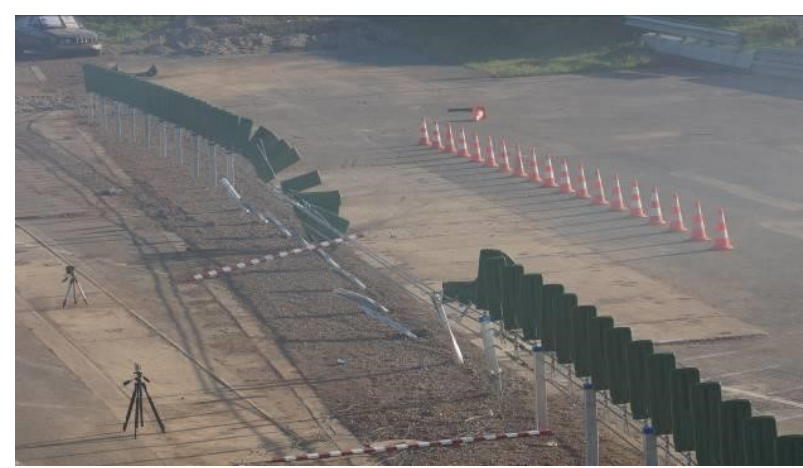

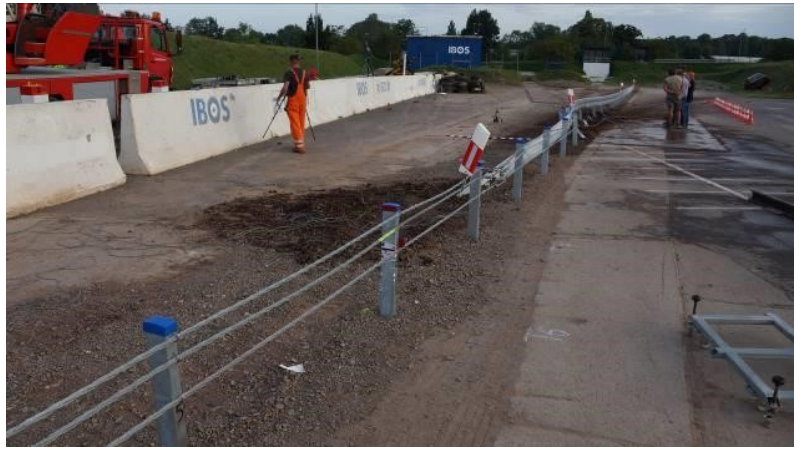
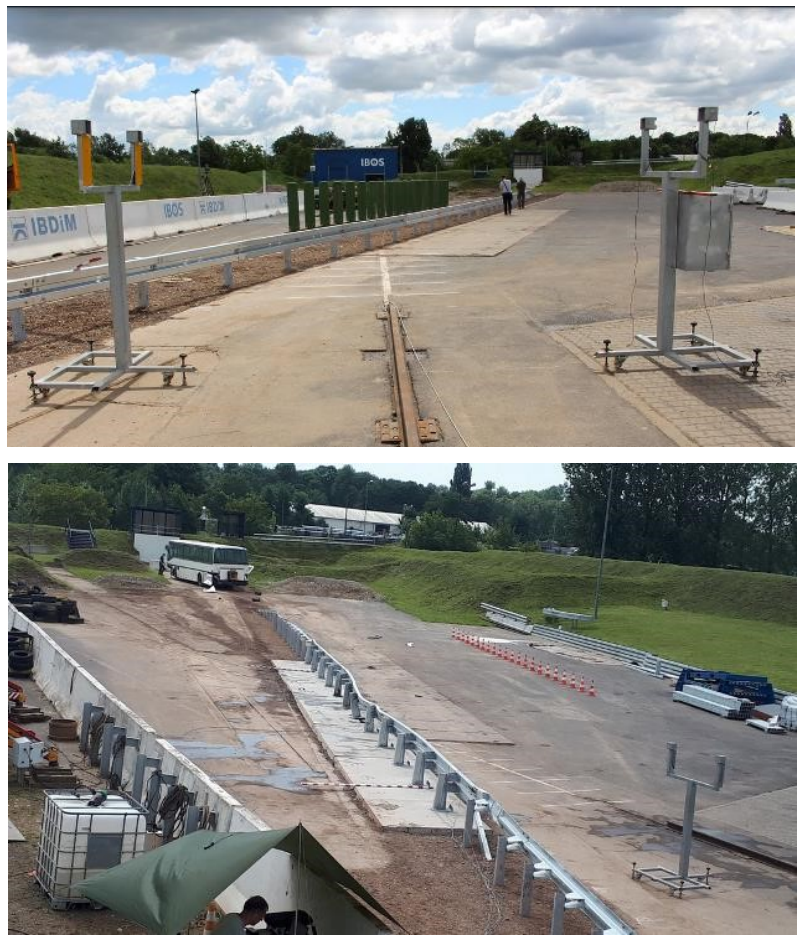

Fig. 2. Sample photos from crash tests

\section{Numerical crash tests}

The main objective of safety barrier modelling and simulation tests is to develop numerical models of crash tests. The work conducted in 2016 included an extensive review of the literature, adjusting vehicle numerical models to the needs of the project and preliminary numerical tests. Building on these results in 2017 further research included simulations of virtual crash tests using a commercial system of the finite elements methods (MES), the Ls-Dyna.

Numerical models were developed for steel barrier TB11 and TB32, wire rope TB32 and concrete barrier TB41 crash tests. The simulations are being validated with results from real crash tests. A series of pilot simulations were conducted to verify the models of the steel guardrail barrier, wire rope barrier and concrete barrier on straight line sections. The system's basic structural element are guardrails mounted to posts using brackets. In addition, for the purposes of the test new models of the wire rope and concrete barriers were made. The first wire rope barrier model consists of three 3 lines attached to posts using hooks which when hit by a vehicle must make sure that the wire rope will detach from the posts 
easily. After a literature study models were selected from the Ls-Dyna's materials library which describe the wire rope's state of tension and include pre-tension. In the posts' model of the steel material real material data were used, obtained from laboratory tests of post samples. The model used selected algorithms to follow the contact between the model's elements. Thanks to this it was possible to represent crashes between the wire ropes modelled as beam elements and the other elements of the numerical model. In the second model of the wire rope barrier which consists of 4 lines separated by a plastic element a different approach was applied to simulating contact between the finite elements which describe the line and coating elements used for the discretisation of the other elements of the model such as posts or the vehicle. The beam elements which create the line axis geometry were assigned the line's mechanical properties. Around those elements an additional non-structural coating was modelled to help with contact description. Both models use pre-tension of the wire ropes. Two models of concrete barriers were made consisting of segments joined with a steel bridge. The model also includes the barrier's internal structure. The first model is a temporary barrier, $46 \mathrm{~m}$ long. The second model is an anchored barrier, $88 \mathrm{~m}$ long. Based on the review of the literature, an advanced model of concrete was used for modelling purposes. It was made specifically to analyse damage to concrete during fast changing events. The model helps to represent the approximated morphology of micro scratches to match the scratches shown in the photographs from the real test. Concrete and steel material data were obtained from laboratory tests using samples from barrier pieces. A detailed description was used of the friction between different materials including the speed of displacement.

Work has also begun on modelling safety barriers on horizontal curves. The current EN 1317 standards for safety barrier crash tests only regulate straight sections of barriers and barriers on horizontal curves are not covered. Using numerical simulations a pilot series of crash tests was conducted with steel and wire rope guard rail barriers on horizontal curves. The analysis looked at different curve radii. Work began on developing numerical MES models for two crash tests consistent with the TB32 crash test (according to standard PN-EN 1317:2010) for safety barriers installed on horizontal curves. The first test was conducted for class N2/W4/A road wire rope barrier and the second for class N2/W4/A road steel barrier. Barrier systems were installed on convex horizontal curves with a radius of $400 \mathrm{~m}$. Fig. 3 . shows the models of these barrier systems and a comparison to a real site test. At present, the models are being validated. They still need anti-glare screens which were used in the site test. Early results of crash intensity are as follows: for the wire rope barrier ASI $=0.57$ (test site result 0.52 ), THIV $=21 \mathrm{~km} / \mathrm{h}$ (test site result 19 $\mathrm{km} / \mathrm{h}$ ), for the steel barrier ASI $=0.62$ (test site result 0.7 ), THIV $=22.3 \mathrm{~km} / \mathrm{h}$ (test site result $23 \mathrm{~km} / \mathrm{h}$ ).
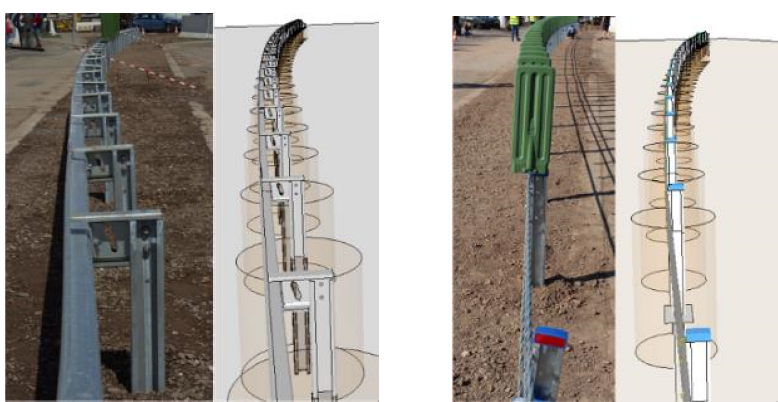

Fig. 3. The numerical model and view of system at a test site, barrier on a horizontal curve, radius $400 \mathrm{~m}$, a) steel barrier, b) wire rope barrier

For the purposes of the task, a detailed programme of numerical safety barrier crash tests was developed. In the first stage a series of calculations were carried out for a concrete barrier and crash tests involving BMW series 5 vehicle, at $1,500 \mathrm{~kg}$. These tests are based on the standard TB32 test and the modifications are applied to the speed and angle of the impact, place of impact and barrier length. Numerical models for these tests were built using a TB41 simulation as the basis. It was validated successfully. The analysed barrier system is not anchored. The total length of the barrier's model is $46 \mathrm{~m}$ and does not have beginnings or terminations. In addition, the same scope of tests will apply to an anchored concrete barrier, $88 \mathrm{~m}$ long, which includes beginning and terminating sections.

Another development is modelling the ground for mounting safety barrier posts. In numerical simulations this was done by introducing a cylinder-shaped base. To post-process the results, in-house programmes and scripts were used to determine acceleration intensity indicators, ASI, the theoretical value of the speed of the head on impact, THIV, working width and dynamic deflection.

Numerical models for numerical vehicle simulations were sourced from generally available on-line libraries as open source. The vehicle model resource was complemented with a BMW numerical model, bought from Transpolis (previously LIER), France. The model is of a $1,500 \mathrm{~kg}$ vehicle and is dedicated to TB32 crash tests. It corresponds to BMW vehicles used in real crash tests. The model has been instrumental for the accuracy and reliability of TB32 crash test calculations. Fig. 4. shows a comparison between the MES model of a BMW vehicle and a real vehicle. The vehicle models were systematically modified in order to solve some issues such as improving the suspension, tyre model and discretisation). a)

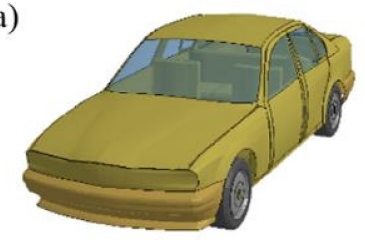

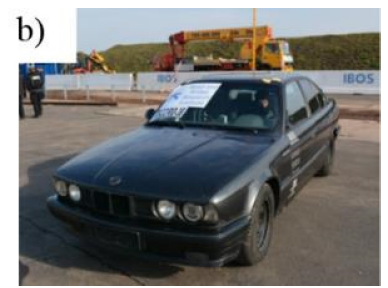

Fig. 4. A BMW vehicle, a) MES model, b) real test vehicle 


\section{Database development}

Understanding how safety barriers change road safety requires in-depth studies such as database exploration and design, conducting numerical tests (based on crash tests) and safety modelling (Fig. 5.). More than seventy sections of national roads with a total length of about $3,000 \mathrm{~km}$ across all of Poland's regions are being monitored for road accidents, road parameters and traffic volumes. The data collected at these sites includes photographic documentation of accidents that involve running into a road safety device (Fig. 6.).

The collected data are used to develop models of road safety measures and methods for managing road safety tools. Similarly to the TRL research [30], as part of observation of how road safety devices operate, various road sections were selected by device (old type, new type, steel, wire rope, concrete) and traffic and road parameters. An important criterion for the selection of sections was the assessment of individual risk [31] of running into safety barriers or poles. Data were divided into three groups: Road Database - containing information about sections, location, geometry, roadside; Traffic Database - containing data on the volume, type of traffic structure; Accident Database - containing data on accidents, victims, circumstances, types, causes, perpetrators, etc.

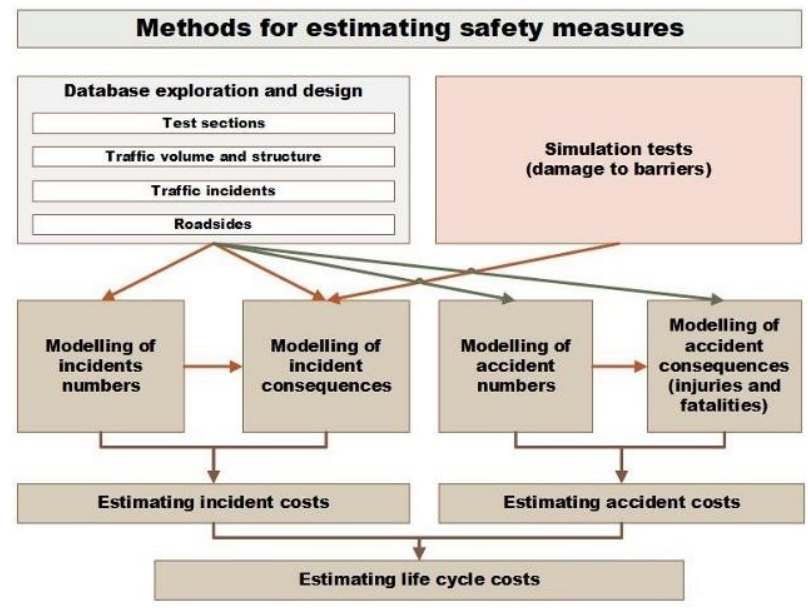

Fig. 5 Diagram of analytical work on road restraint systems.

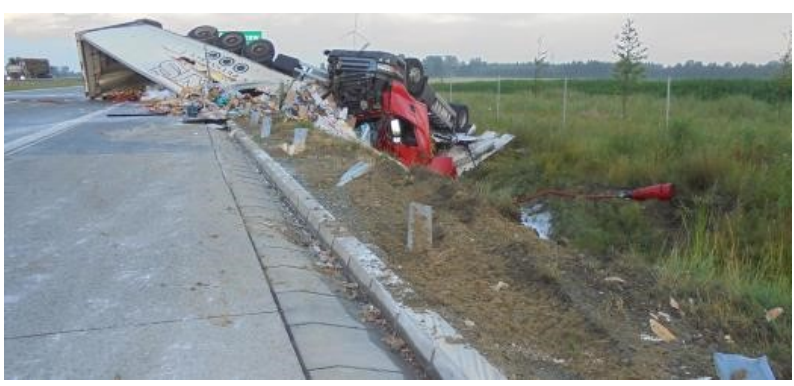

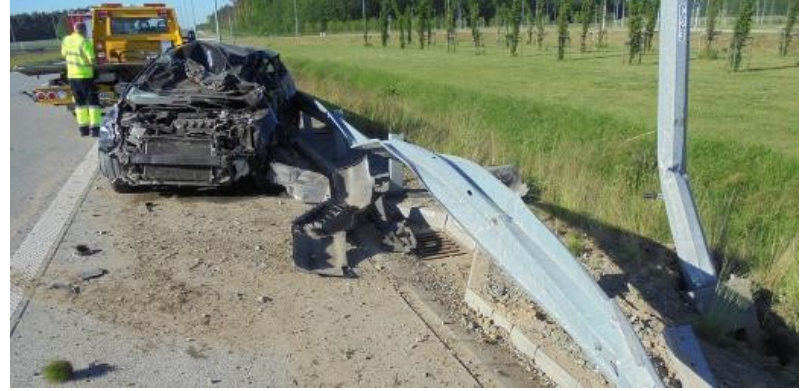

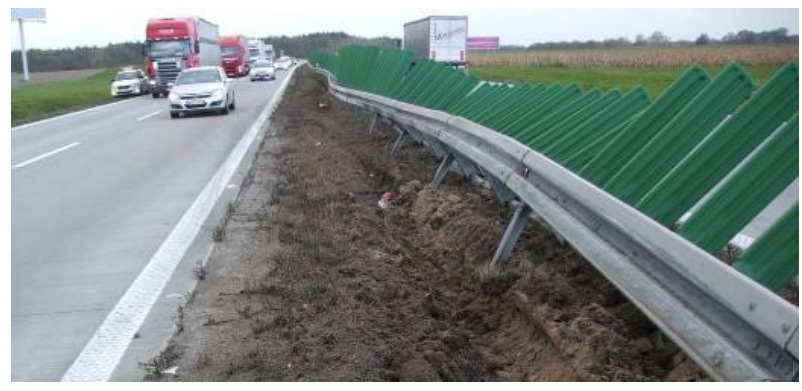

Fig. 6. Photographic documentation of road accidents /source: General Directorate of National Roads and Motorways/

\section{Hazard identification and road safety measure models}

Sections of national roads which have recorded roadsiderelated accidents (hitting a tree, utility pole, sign, barrier, vehicle roll-over on the shoulder, on an embankment, in a ditch) within the last 5 years were analysed in detail. Fig. 7. shows a map of the most dangerous sections of national roads in the particular regions. A detailed road safety inspection will be conducted for each of the sections to identify the hazards and suggest treatments.

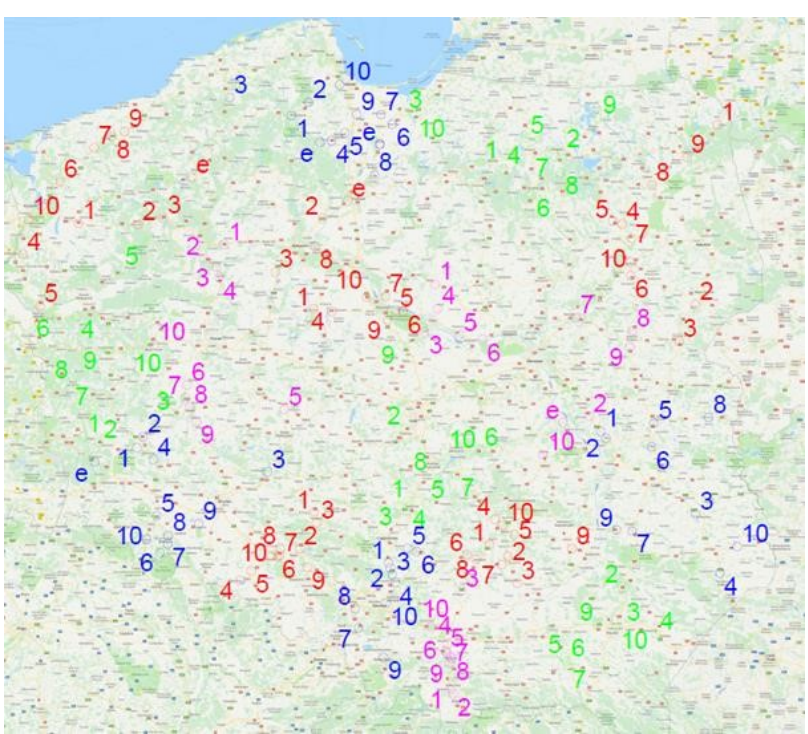

Fig. 7. Map of the most hazardous sections due to roadside conditions in the regions

A report was drafted showing the results of an analysis and classification of improper use of road safety devices and hazards and sources of hazards if there are no restraints or the restraints are wrongly used. The 
example used in this case was the region of Pomorskie. Fig. 8. shows an example of an analysis of a hazardous road section with the possibility of a run-off-road accident. Fig. 9. gives an example of hazards identified during a road safety inspection on a national road.

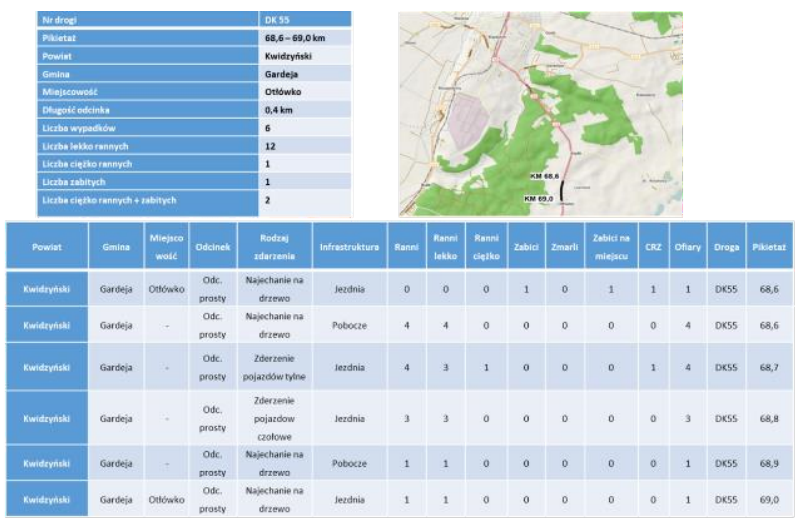

Fig. 8. Analysis of a selected section of national road 55
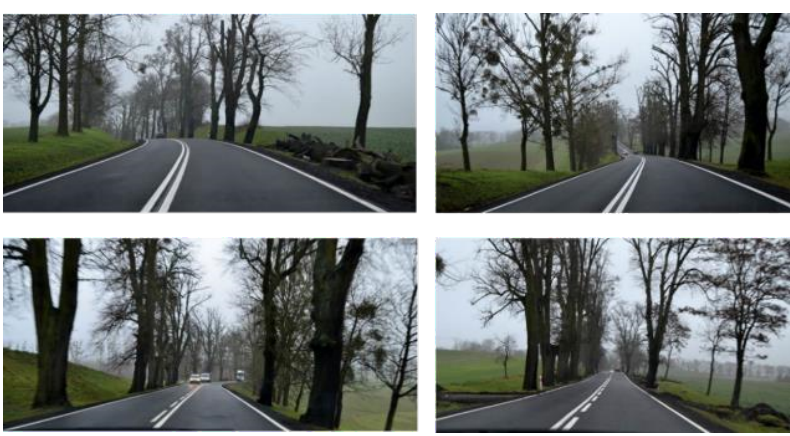

Fig. 9. Identification of hazards on section of NR road 55

Table 1. Parameter estimates of the crash prediction model of Eq. (1)

\begin{tabular}{|l|l|l|}
\hline Parameter & Coefficients & Value \\
\hline Adjustment & $\alpha$ & 0.01 \\
\hline Traffic volume Q & $\beta_{1}$ & 0.79 \\
\hline \% of barriers B & $\beta_{2}$ & -2.03 \\
\hline$\%$ of embankments S & $\beta_{3}$ & 1.25 \\
\hline \% of trees to 3.5m $\mathrm{T}_{1}$ & $\beta_{4}$ & 2.87 \\
\hline \% of trees above 3.5m $\mathrm{T}_{2}$ & $\beta_{5}$ & -0.58 \\
\hline$\%$ of forests $\mathrm{T}_{3}$ & $\beta_{6}$ & -0.38 \\
\hline Road class C & $\beta_{7}$ & -2.90 \\
\hline$\%$ of shoulders above 1.5 & $\beta_{8}$ & -0.47 \\
\hline \% of shoulders to $1.5 \mathrm{~m} \mathrm{P}_{2}$ & $\beta_{9}$ & -0.10 \\
\hline \% of soft shoulders $\mathrm{P}_{3}$ & $\beta_{10}$ & 0.38 \\
\hline
\end{tabular}

The database includes parameters assigned to reference lengths from $1-5 \mathrm{~km}$, which are: length of section, annual average daily traffic flow, number of intersections and exits, share of sections with barriers, share of sections with trees, number of signs, posts and other road furniture. According to the recommendations (based on the analysis of other models) the following assumptions were developed:
- model to be used to calculate risk index and severity of events,

- risk index will depend on traffic volume,

- the analyses to be based on the existing data on accidents: hitting a barrier, running into a tree, running into a pole or sign,

- the results to distinguish between cross-sections (single and dual carriageway) and classes.

The results of the study are presented based on the DA victims density model for single carriageway roads of GP class (main road with accelerated traffic) outside a built-up area. The accident density model is described with the following formula:

$\left.\mathrm{DA}=\alpha \cdot Q^{\beta_{1}} \cdot e^{\left(\mathrm{B}^{\beta_{2}}+S^{\beta_{3}}+T_{1}^{\beta_{4}}+T_{2}{ }^{\beta 5}+T_{3}{ }^{\beta 6}+C^{\beta 7}+P_{1}^{\beta_{8}}+P_{2}^{\beta_{9}}+P_{3}^{\beta 10}\right.}\right)$ (1)

where:

DA kilometres of road

expected number of accidents per $\alpha \quad$ adjustment coefficient Q annual average daily traffic (AADT)

$\beta \mathrm{j}(1,2, \ldots, \mathrm{n}) \quad$ calculation coefficients

$\mathrm{B}, \mathrm{S}, \mathrm{T}_{1}, \mathrm{~T}_{2}, \mathrm{~T}_{3} \mathrm{C}, \mathrm{P}_{1}, \mathrm{P}_{2}, \mathrm{P}_{3}$ factors related to the risk of an accident

In the case of the DA victims density model, the determination coefficient is 0.72 . The factors with the strongest effect on the model had to do with barriers, number of trees along the carriageway (up to 3.5 and more than $3.5 \mathrm{~m}$ from the edge), number of barriers and road class. The study showed that accident density goes down as the number of barriers and hard shoulders goes up. When all the other parameters are averaged and the effects of AADT are included, DA shows a clear increase for more than a $60 \%$ share of sections with roadside trees that are less than $3.5 \mathrm{~m}$ away from the road edge and no barriers are present. Where safety barriers are present, DA drops significantly for sections with roadside trees more than $3.5 \mathrm{~m}$ away from road edge and embankments. As the work continues, it will study a greater level of detail: the height and gradient of slopes, presence of obstacles, share of heavy goods vehicles, type of safety barriers, roadway width, different cross-sections (single and dual carriageways, $2+1$ crosssection).

\section{Summary}

Over the last twenty five years more than 20,000 people were killed on Polish roads in run-off-road crashes (of which a clear majority involved hitting a tree). The main factors that influence the risk of being involved in such a crash are: historic developments, road class, length and element of carriageway, hazardous elements at the edge of carriageway (mainly trees), safety measures in place or lack of safety measures. To improve roadside safety we must: identify the hazards on the road network, conduct checks, conduct research (build models of the effects of selected factors on road safety, effectiveness evaluation), implement safety standards, develop guidance and principles for safe roadsides, ensure that 
there is collaboration between designers, road authorities and environmental organisations and institutions and exchange experience with other countries. More models should be developed that combine road hazards with the risk of accidents, with particular emphasis on the impact of road restraint systems. For years roadside environments have been one of the most neglected aspects of road safety efforts in Poland. Clarity is needed on the effects of roadsides on road safety. We must understand the hazards roadsides cause and implement effective solutions.

Acknowledgements Research is funded by the Development of Road Innovation research programme, project RID 3A (contract number DZP/RID-I-67/13/NCBR/2016), and ordered by: The National Centre for Research and Development (NCBiR) and the General Directorate for National Roads and Motorways (GDDKiA).

\section{References}

1. M. Budzynski, K. Jamroz, L. Jelinski, and M. Antoniuk, "Why are Trees Still Such a Major Hazard to Drivers in Poland?," in Transportation Research Procedia, 2016, vol. 14.

2. M. A. Cafiso S., Cava G. La, "Identification of hazard location and ranking of measures to improve safety on local rural roads Final research report," 2007.

3. J. W. H. Van Petegem and F. Wegman, "Analyzing road design risk factors for run-off-road crashes in the Netherlands with crash prediction models," $J$. Safety Res., vol. 49, no. February, pp. 121-127, 2014.

4. Aashto, Roadside Design Guide. 2011.

5. C. Brodie, C. Jurewicz, L. Steinmetz, C. Phillips, P. Cairney, and G. Veith, Improving Roadside Safety Summary Report. .

6. Yannis G., Best practice for cost - effective road safety infrastructure investments. 2008.

7. C. D. Fitzpatrick, C. P. Harrington, M. a. Knodler, and M. R. E. Romoser, "The influence of clear zone size and roadside vegetation on driver behavior," $J$. Safety Res., vol. 49, no. February, pp. 97-104, 2014.

8. J. Hills G., L., Baguley C., J., Kirk S., Cost and Safety Efficient Design Study of Rural Roads in Developing Countries Final Report Countries. 2002.

9. S. Vardaki, F. Papadimitriou, and P. Kopelias, "Road safety audit on a major freeway: implementing safety improvements," Eur. Transp. Res. Rev., vol. 6, no. 4, pp. 387-395, 2014.

10. J. Lee and F. Mannering, "Impact of roadside features on the frequency and severity of run-offroadway accidents: an empirical analysis," Accid. Anal. Prev., vol. 34, no. 2, pp. 149-61, Mar. 2002.

11. F. La Torre, P. Saleh, E. Cesolini, and Y. Goyat, "Improving Roadside Design to Forgive Human Errors," Procedia - Soc. Behav. Sci., vol. 53, pp. 235-244, Oct. 2012.
12. F. A. Burlacu, O. Tarita-Cimpeanu, and M. Dicu, "The Need for Safer and Forgiving Roads," Proc. Int. Conf. Road Rail Infrastruct. CETRA, Apr. 2014.

13. N. Jamieson, G. Waibl, and R. Davies, "RR 517 Use of roadside barriers versus clear zones," 2013.

14. J. M. Holdridge, V. N. Shankar, and G. F. Ulfarsson, "The crash severity impacts of fixed roadside objects," J. Safety Res., vol. 36, no. 2, pp. 139-147, Jan. 2005.

15. AASHTO, Highway Safety Manual. Washington: American Association of State Highway and Transportation Officials, 2010.

16. S. de Ridder, R. van der Horst, and R. Thomson, "D04: Envelope of vehicle and driver response prior to collisions Project ACRONYM: RISER TITLE: Roadside Infrastructure for Safer European Roads," Sustain. Growth' Program., 1998.

17. R. Elvik and T. Vaa, The handbook of road safety measures. Elsevier, 2005.

18. S. Gaca and M. Kiec, "Speed Management for Local and Regional Rural Roads," Transp. Res. Procedia, vol. 14, pp. 4170-4179, 2016.

19. S. Gaca, M. Kiec, and M. Budzynski, "Evaluating the effectiveness of non-physical speed management measures- Web of Science Core Collection Full Record," 2016, pp. 627-633.

20. F. La Torre, G. Williams, R. Thomson, and C. Stefan, "CEDR Call 2012: Safety: Use of Vehicle Restraint Systems SAVeRS Selection of Appropriate Vehicle Restraint Systems Guideline for the selection of the most appropriate Roadside Vehicle Restraint System," 2015.

21. J. D. M. H. E. ROSS, JR., D. L. SICKING, R. A. ZIMMER, "National Cooperative Highway Research Program Report 350,” 1993.

22. "AASHTO/FHWA Joint Implementation Agreement for the AASHTO Manual for Assessing Safety Hardware, 2015," p. 2015, 2019.

23. Z. Ren and M. Vesenjak, "Computational and experimental crash analysis of the road safety barrier," Eng. Fail. Anal., vol. 12, no. 6, pp. 963973, Dec. 2005.

24. M. Borovinšek, M. Vesenjak, M. Ulbin, and Z. Ren, "Simulation of crash tests for high containment levels of road safety barriers," Eng. Fail. Anal., vol. 14, no. 8, pp. 1711-1718, Dec. 2007.

25. I. Kreja and M. L. Wekezer, Jerry W, "Computer simulation of vehicle collisions with road safety devices," Road Constr., vol. 8, 2000.

26. M. Vesenjak, M. Borovinšek, and Z. Ren, "Computational simulations of road safety barriers using LS-DYNA," 2007.

27. M. Klasztorny, D. B. Nycz, and P. Szurgott, "Modelling and simulation of crash tests of N2-W4A category safety road barrier in horizontal concave arc," Int. J. Crashworthiness, vol. 21, no. 6, pp. 644-659, Nov. 2016. 
28. M. Klasztorny, K. Zielonka, D. B. Nycz, and P. Posuniak, "Experimental verification of simulation of tb32 crash test for $\mathrm{sp}-05 / 2$ road safety barrier on horizontal concave arc," J. Civ. Eng. Environ. Archit., vol. z. 64, nr 2/I, 2017.

29. K. Wilde, K. Jamroz, D. Bruski, S. Burzyński, J. Chróścielewski, and W. Witkowski, "Numerical study of bus collision in barrier system and truss support structure," J. Civ. Eng. Environ. Archit., 2016.

30. G. L. Williams, "Whole Life Cost-Benefit Analysis for Median Safety Barriers."

31. W. Kustra, K. Jamroz, and M. Budzynski, "Safety PL- A Support Tool for Road Safety Impact Assessment," in Transportation Research Procedia, 2016, vol. 14. 